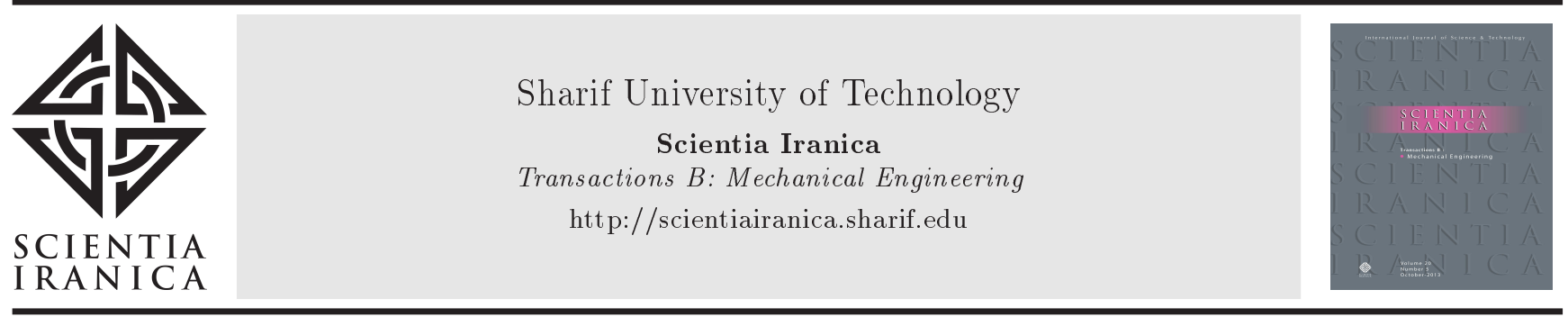

\title{
Comparison of the effect of temperature parameter on the functionality of tracking and fixed photovoltaic systems: A case study in Tehran, Iran
}

\author{
M.M. Darian ${ }^{\mathrm{a}, *}$ and A.M. Ghorreshi ${ }^{\mathrm{b}}$ \\ a. Faculty of Mechanical and Energy Engineering. Shahid Beheshti University, A.C., Tehran, Iran. \\ b. Faculty of Industrial Engineering, Raja University, Ghazvin, Iran.
}

Received 6 January 2020; received in revised form 10 April 2020; accepted 3 August 2020

\section{KEYWORDS \\ Temperature; \\ Renewable energy; \\ Photovoltaic system; \\ Efficiency; \\ Fixed and tracking.}

\begin{abstract}
Production of energy by renewable energy including photovoltaic systems is always dependent on the environmental and geographical parameters based on which these system are installed. Temperature is one of the most important environmental parameters that affects the performance of photovoltaic systems. The effect of this parameter on the functionality of fixed and tracking photovoltaic systems is not the same. Since it is exposed to the sun from sunrise to sunset, the tracking photovoltaic system has a higher temperature on the surface of the panels than the fixed photovoltaic systems. The result of the experiments in this study showed that the temperature-induced efficiency decline rates for the fixed and tracking photovoltaic systems were more than $7.98 \%$ and $10.02 \%$, respectively. According to calculations, the temperature-induced efficiency drop in tracking photovoltaic systems was about $25.55 \%$ higher than that in fixed photovoltaic systems. Observations showed that the temperature difference was on full display at sunrise and sunset, while this difference was minimized around noon.
\end{abstract}

(C) 2021 Sharif University of Technology. All rights reserved.

\section{Introduction}

Environmental pollutions and limited extent of fossil fuels have prompted human societies to switch to clean and renewable energies to produce energy $[1,2]$. Fossil fuels are still the main source of energy production [3]. However, using renewable energies has been increasing in recent decades [4], as it is predicted that $16 \%$ of the required electricity of the world will be generated by renewable energies by 2035 [5]. Renewable energies,

*. Corresponding author.

E-mail address: Mahdi.mirzaeimmm@gmail.com (M.M. Darian)

doi: $10.24200 /$ sci. 2020.55173 .4102 unlike fossil fuels, are available in many parts of the world and they can be employed to produce energy, even in remote areas [6].

Among renewable energies, the sun is the dominant source of energy that can easily be converted to other types of energy such as thermal, electrical, and chemical energies [7]. Photovoltaic systems are one of the mechanisms that can be used for producing electrical energy using sunlight [8]. Using solar energy for energy production is increasingly growing [9] Electricity production using photovoltaic systems is highly dependent on the environmental and geographical situations of the site being used. Sunlight intensity, temperature, humidity, dust, and wind are some of the influencing environmental factors [10].

Temperature is one of the most important envi- 
ronmental factors influencing the efficiency of photovoltaic systems [11]. It causes a reduction in the voltage of the photovoltaic system, which, in turn, leads to a reduction in the power generated by the system [12]. Typically, upon a $1^{\circ} \mathrm{C}$ increase in temperature, $0.45 \%$ of the efficiency of the system is reduced [13]. Another important environmental factor is dust effect. An increase in the dust amount in air and on panel surfaces reduces the sunlight reaching the solar cells, thus reducing the efficiency $[14,15]$.

In addition to all of the advantages of photovoltaic systems for energy production, low efficiency and capacity factor are one of the main problems in these systems. To this end, one possible solution is using tracking systems. In tracking systems, panels are always facing the sun. This causes an increase in system production. Many research pieces have investigated and compared the energy produced by these two systems [16-21]. A comparison between fixed and tracking photovoltaic systems in different geographical areas may produce different results [22$28]$. The rate of increase in the yield of tracking systems in hot and cold geographic regions varies. For example, according to a study specific to Germany, the difference in the output power of fixed and tracking systems is $39 \%$, while it is $8 \%$ in Egypt [26].

Environmental parameters, sometimes, have different effects on fixed and tracking photovoltaic systems. Some portion of the dust may touch and remain on tracking systems due to its permanent movement during the day. Besides, tracking systems are always facing the sun directly. Consequently, the surface temperature of these panels goes higher than that of fixed systems [13,29]. However, the main question is how much the temperature increase on the surface of tracking panels is. Is it significant enough to exert a tangible influence on energy production of the tracking systems? Or is it too inconsiderable to be neglected and ignored?
In this study, the difference in the temperature of the surfaces of fixed and tracking photovoltaic panels will be investigated and compared. This research has already been investigated in brief by a number of studies, qualitatively. However, in this study, the investigations are quantitative so as to evaluate and determine the effectiveness of temperature parameters in the functionality of the systems. This is performed by the PVSyst 6.4.3 software, at first, and the calculations are done. Then, the results obtained from the simulations are verified by conducting an experiment.

\section{Materials and methods}

This section describes the existing materials in the laboratory and how to use them in testing. The simulation method performed here will be elaborated, as well. The software used as well as the assumptions intended for this simulation will be examined.

\subsection{System description}

This experiment was carried out in the Technical and Engineering Campus of Shahid Beheshti University, east of Tehran, with latitude 35.7426 and longitude 51.5788. The fixed system consisted of 57 panels $(255 \mathrm{~W})$ that were connected to the end of three inverters $(5 \mathrm{~kW})$. The panels were installed on the rooftop of one of the university's buildings to the south at an angle of 30 degrees. The power generated in the system is eventually injected into the power grid (Figure 1).

The tracking system is a single-axis type installed towards the south at an angle of 30 degrees and follows the sunrise and sunset. The control system is configurable and follows the sunlight using the program compiled on its controller. The system consists of nine $255 \mathrm{~W}$ panels. The specifications of the panels are given in Table 1. The panel's output is connected to

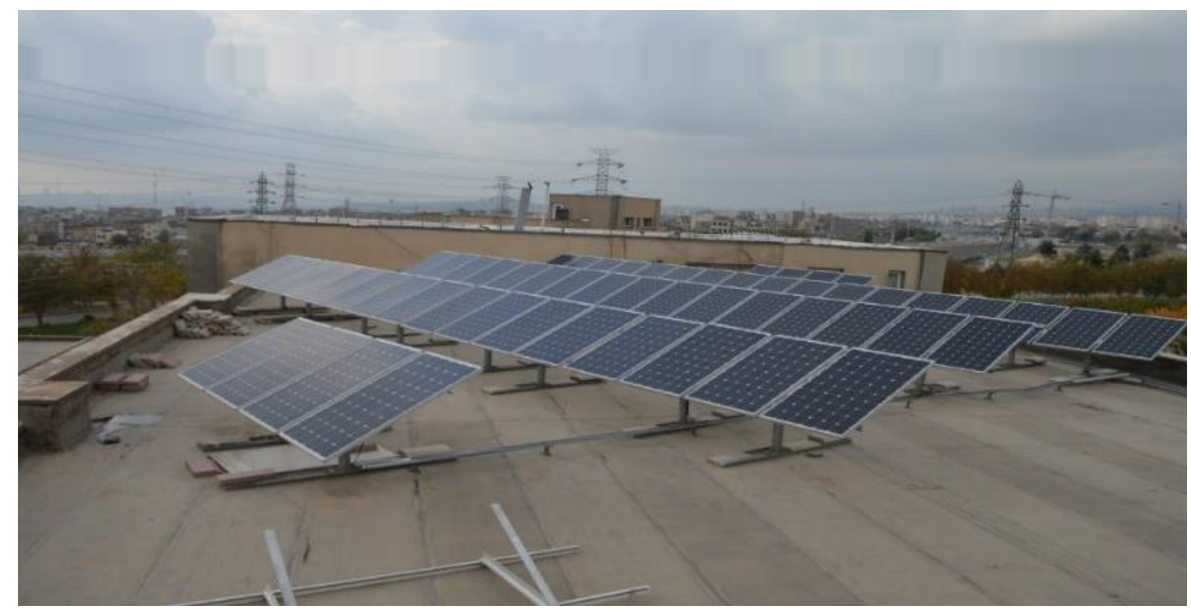

Figure 1. Fixed photovoltaic system in Shahid Beheshti University (SBU). 
Table 1. Photovoltaic (PV) module technical specifications [37].

\begin{tabular}{ll}
\hline \multicolumn{1}{c}{ PV module } & \multicolumn{1}{c}{ Specifications } \\
\hline Model & Conergy PE 255 \\
Type & Monocrystalline Silicon \\
Number of cell & 60 \\
Nominal Power at STC (PSTC) & 255 \\
Module efficiency & $15.59 \%$ \\
Maximum power current (Impp) & $8.42 \mathrm{~A}$ \\
Maximum power voltage (Vmpp) & $30.29 \mathrm{~V}$ \\
Short circuit current (Isc) & $8.98 \mathrm{~A}$ \\
Open circuit voltage (Voc) & $37.82 \mathrm{~V}$ \\
Power temperature coefficient & $0.43 \% /{ }^{\circ} \mathrm{C}$ \\
\hline
\end{tabular}

an inverter of $2.5 \mathrm{~kW}$ and the generated electricity is eventually injected into the power grid (Figure 2).

The surface temperature of the panels is measured every 5 minutes and recorded. To increase the reliability coefficient, the temperature of two different panels was measured simultaneously and averaged. Temperature was measured using a TM-925 thermometer.

Sunny Webbox was employed for data logging of existing systems (version-M2). With this tool at hand, information about the fixed and tracking systems is recorded every 5 minutes. Weather data such as temperature, wind speed, and irradiance are also recorded with the implementation of sensors available at Sunny Webbox.

PVSyst is designed to be used by architects, engineers, and researches. It features a help menu that explains the used models and methods. This tool presents results in the form of a full report, specific graphs, and tables. Also, data can be employed for use by other software [30].

\subsubsection{System modeling}

In this simulation, for ease of system design, each system was considered $10 \mathrm{~kW}$. Each of these systems consisted of forty solar panels, individually producing $250 \mathrm{~W}$, and two $5 \mathrm{~kW}$ inverters. To increase the simulation accuracy of the software, the panels and inverters similar to the ones in the laboratory were used.

\section{Result and discussion}

This section calculates the loss of temperature-induced efficiency for the fixed and tracking systems by the software. Then, this efficiency decline can be calculated through experimentation and comparison of the results obtained from the simulation.

\subsection{Simulation}

The results of the simulation show that the loss of temperature-induced efficiency for the fixed and tracking systems is $9.2 \%$ and $11.1 \%$, respectively (Figures 3 and 4). According to the obtained numbers, the temperature-induced efficiency drop in the tracking photovoltaic system is $20.65 \%$ higher than that in the fixed photovoltaic system. These calculations show that the photovoltaic tracking system is much more susceptible to temperature damage than the fixed photovoltaic system. In the next section, the results will be validated by field experiments.

\subsection{Experimental analysis}

This experiment was carried out on May 16th, 2019. The temperature of the air as well as fixed and tracking photovoltaic systems are shown in Figure 5. As shown in Figure 5, the temperature of the fixed system panels is close to air temperature during the morning and evening. The reason for this is the maximum possible angle between panels and sunlight beams. Thus, during these hours, the lowest energy is received by the panels from the Sun. The energy produced by the panels is

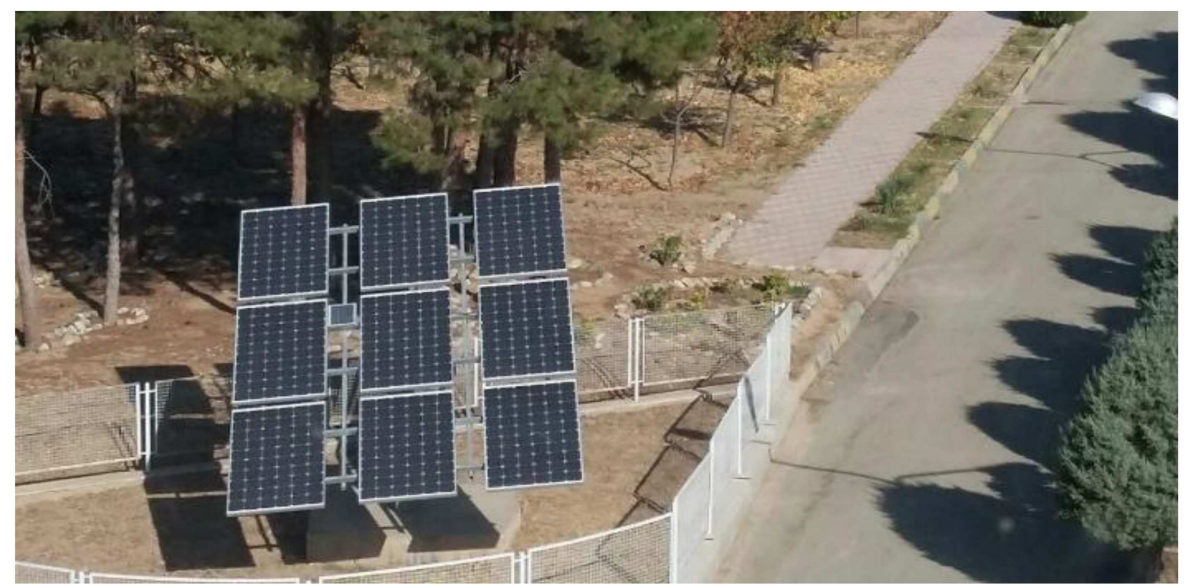

Figure 2. Tracking photovoltaic system in Shahid Beheshti University (SBU). 


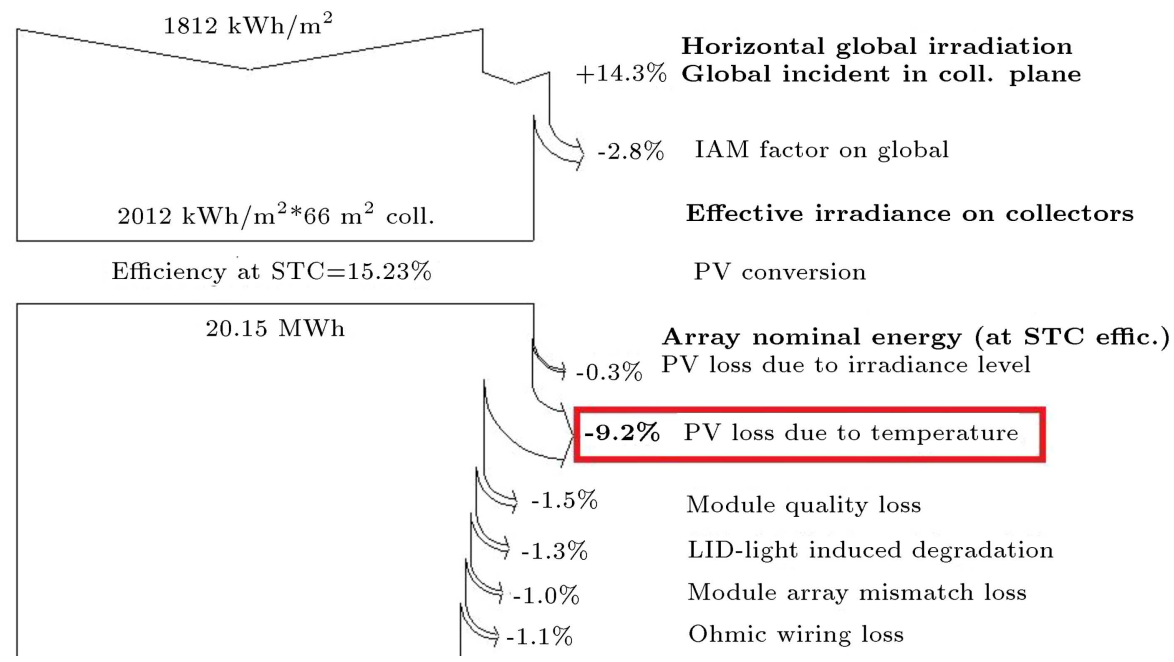

Figure 3. Decrease in efficiency due to temperature in the fixed photovoltaic system.

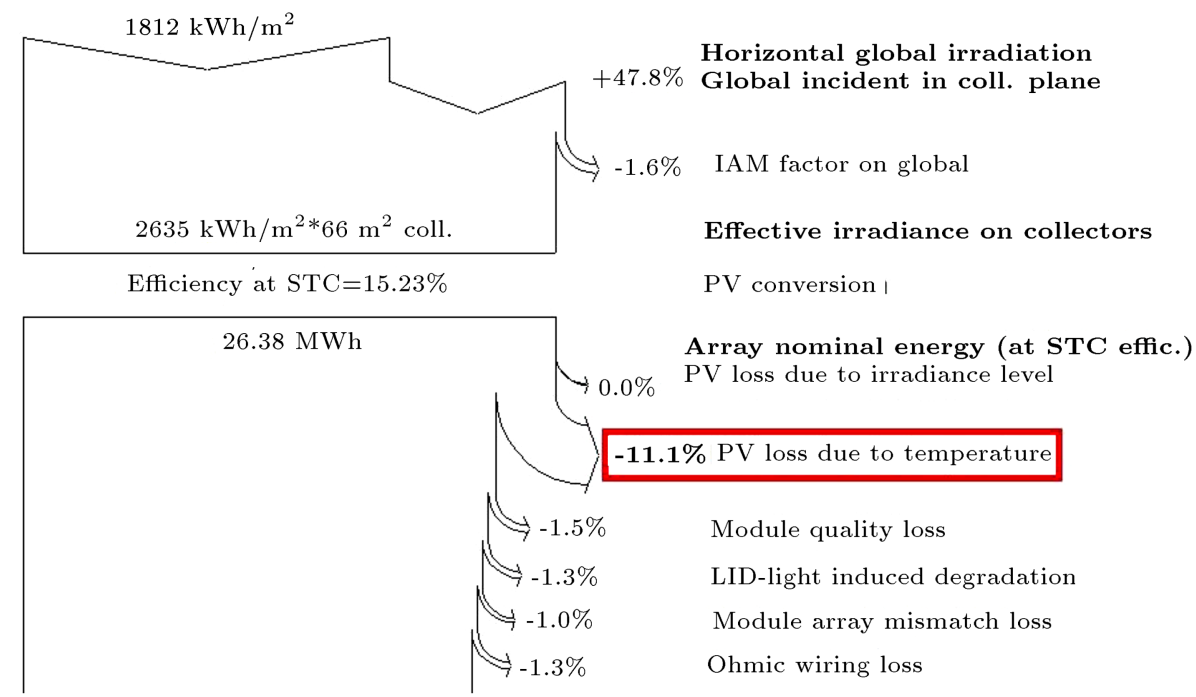

Figure 4. Decrease in efficiency due to temperature in the tracking photovoltaic system.

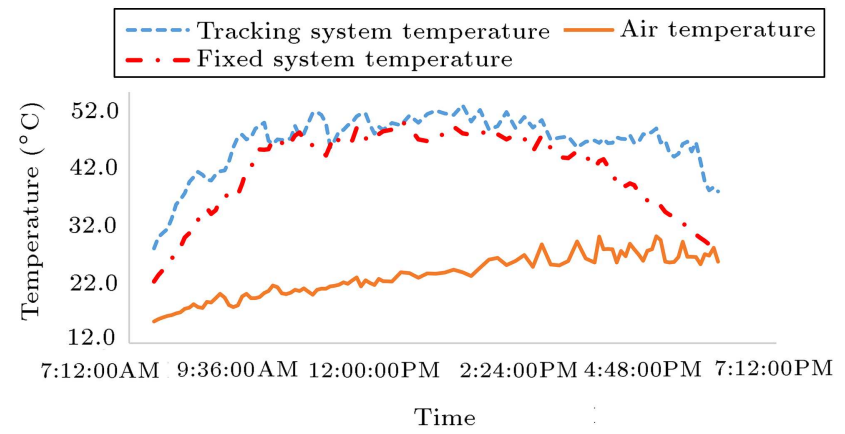

Figure 5. Temperature of the air as well as fixed and tracking photovoltaic systems.

also minimal at this time. As a result, the temperature of the fixed system panels is very low at these hours and is close to the air temperature. However, at the same time, the tracking system panels are facing the sun directly. This has led to the production of these panels during sunrise and sunset. Therefore, the surface temperature of the panels is higher than the air temperature at this time.

The air temperature is reduced from the temperature of the fixed and tracking system panels in Figure 6 to provide a better comparison between the fixed and tracking systems.

Each chart is also fitted with a 5-degree chart to check out, more accurately, the movement of temperatures throughout the day (Eq. (1) for the fixed system and Eq. (2) for the tracking system). As can be seen in Figure 6, the temperature of the fixed and tracking panels is very close to each other at noon, and the further it moves from the noon to the sunrise and sunset, the wider the temperature difference will be. Generally, at the test hours, the average temperature of the tracking and fixed system panels was $45.02^{\circ} \mathrm{C}$ 


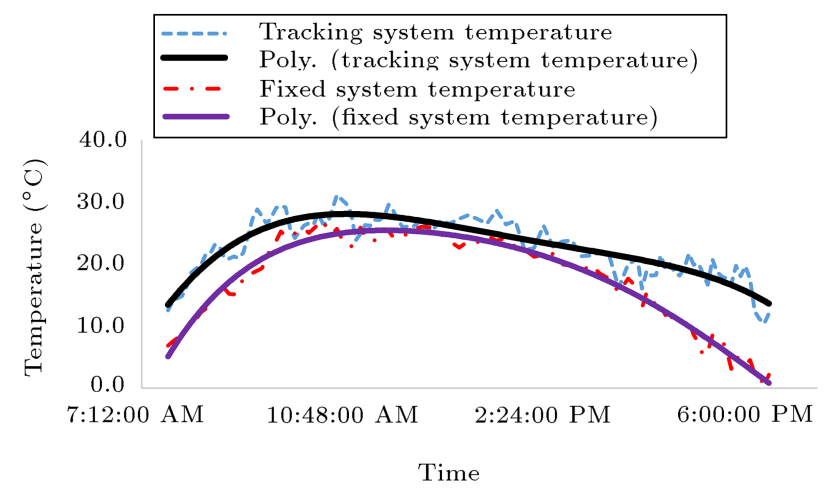

Figure 6. The temperature of the fixed and tracking photovoltaic systems with lower ambient temperature.

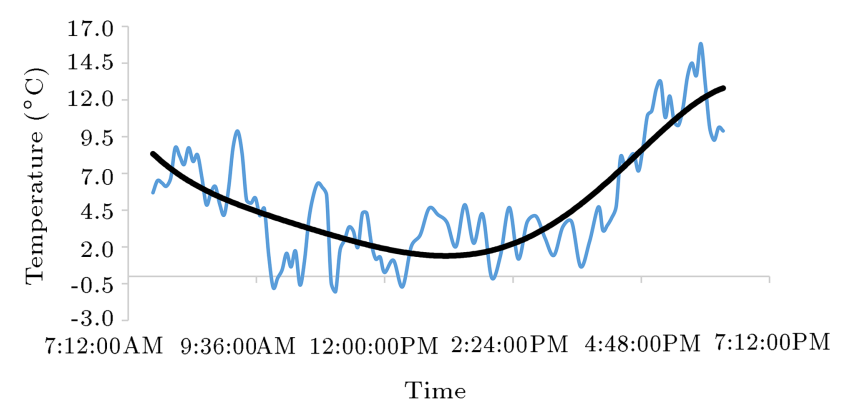

Figure 7. The temperature of the tracking system, with the fixed system temperature being lower.

and $40.94^{\circ} \mathrm{C}$, respectively. According to the results, the average temperature of tracking system panels on this day was $12.2 \%$ higher than that of the fixed system panels. The average air temperature was $23.25^{\circ} \mathrm{C}$ on this day.

$$
\begin{aligned}
y= & -1530.4 x^{5}-172.82 x^{4}+5761.6 x^{3}-6658.5 x^{2} \\
& \quad-2870.5 x-404.98 \\
y= & 11102 x^{5}-33221 x^{4}+39416 x^{3}-23487 x^{2} \\
& +7053.6 x-827.23
\end{aligned}
$$

In Eqs. (1) and (2), $x$ and $y$ denote time and temperature, respectively.

As shown in Figure 7, the temperature of the fixed panels is lowered by the temperature tracking panels. The diagram shows the temperature difference between the tracking and fixed panels (Eq. (3)). Figure 7 clearly shows that there is the highest temperature difference between the panels in the morning and evening, and as it approaches the noon hours, the angles of the panels approach each other. This allows the surface temperatures of the panels to approach each other and minimize the temperature difference between them.

$$
\begin{aligned}
y= & -12633 x^{5}+33048 x^{4}-33654 x^{3}+16829 x^{2} \\
& -4183.1 x+422.25
\end{aligned}
$$

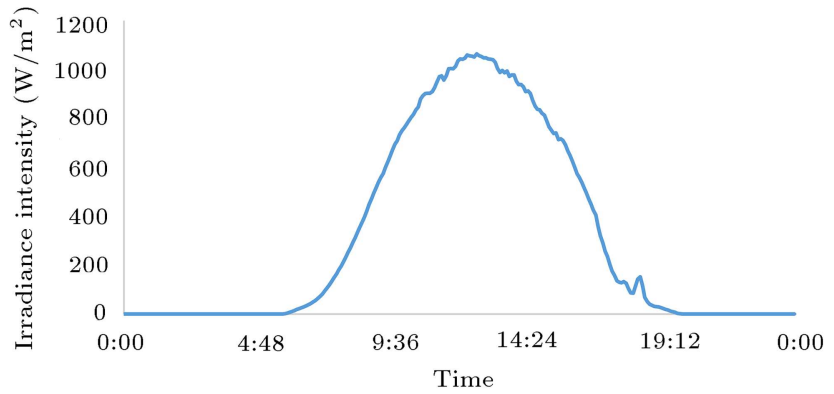

Figure 8. Intensity of sun's Irradiance.

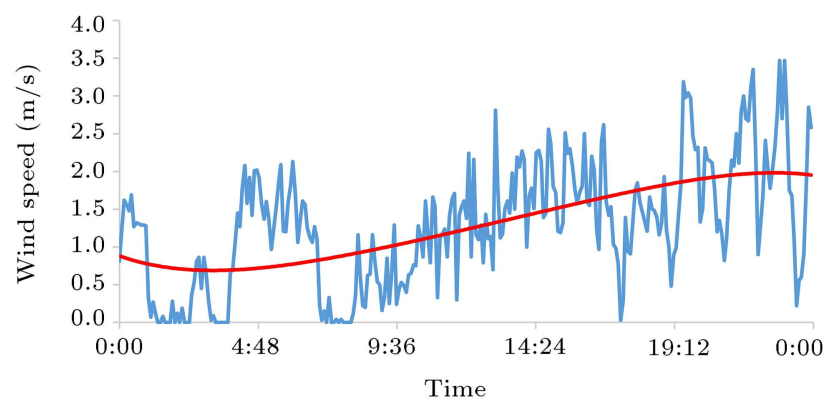

Figure 9. Wind speed during the test day.

where $x$ and $y$ represent time and temperature, respectively.

Due to the importance of other environmental parameters such as radiation and wind and their influence on the temperature parameter, these environmental parameters were measured in this study, as shown in Figures 8 and 9. In Figure 9, the wind speed diagram is highly fluctuating and, so, the curves are fitted to the following equations (Eq. (4)) to better visualize the wind behavior on this day.

$$
\begin{aligned}
y= & -9.42 x^{5}+24.72 x^{4}-27.74 x^{3}+16.74 x^{2} \\
& -3.22 x+0.88
\end{aligned}
$$

where $x$ and $y$ represent time and wind speed, respectively.

In the experiments performed in this study, the temperature of the back surface of the panels was measured. To determine the rate of temperature drop on the panels, it is necessary to calculate the surface temperature of the photovoltaic cells. After determining the temperature of the back surface of the panels, the surface temperature of the photovoltaic cells is obtained using Eq. (5) [13]:

$$
T_{c}=T_{m}+\Delta T \times\left(G / G_{S T C}\right) .
$$

In this case, $T_{c}$ and $T_{m}$ are the photovoltaic cell temperature and the surface temperature behind the panel, respectively. $\Delta T$ is the fixed number equal to 3 [31]. $G$ is the intensity of ambient radiation on the test day, and $G_{S T C}$ is the standard radiation intensity 
(1000 W/ $\left.\mathrm{m}^{2}\right)$. According to Eq. (5), the surface temperature of the panels in fixed and tracking systems is $43.56^{\circ} \mathrm{C}$ and $48.31^{\circ} \mathrm{C}$, respectively. Accordingly, the surface temperature of photovoltaic cells in the tracking systems is $10.91 \%$ higher than that of the fixed systems.

Given the surface temperature of the cells, the efficiency of each system can be calculated. According to the catalog of available panels, due to the structural features of the panels used, upon increasing temperature by $1^{\circ} \mathrm{C}$, the power of the panels decreases by $0.43 \%$ (power temperature coefficient) (Table 1). Therefore, the power drop due to the temperature in the panels is calculated using Eq. (6):

$$
P_{\mathrm{Loss}}=\left(T_{C}-T_{S T C}\right) \times 0.43,
$$

where $P_{\text {Loss }}$ is the power drop due to the temperature in the panels, which is obtained as a percentage and $T_{S T C}$ is the temperature under standard conditions $\left(25^{\circ} \mathrm{C}\right)$. Therefore, 0.43 is also power temperature coefficient.

According to Eq. (6), the loss of temperatureinduced efficiency in the fixed and tracking systems is $7.98 \%$ and $10.02 \%$, respectively. Accordingly, the tracking systems are $25.55 \%$ more vulnerable to temperature than fixed systems. Figure 10 shows the results of the conducted experiment and simulation.

According to the results obtained from the simulation and experiments, the surface temperature of the panels in the tracking systems is higher than that of the panels in the fixed systems. This indicates that the tracking systems are highly affected by the temperature parameter. This means that if the panels in the tracking systems can be cooled, the efficiency of the system will increase significantly. There are different ways to cool down the panels. One of these solutions is using photovoltaic thermal panels. These panels function by reducing the heat on the surface of the panels and extracting the heat obtained [3236]. Using these panels in photovoltaic systems can yield a very positive effect. Moreover, upon lowering the temperature of the panels, the overall efficiency of the system increases and there is a great deal of thermal energy. According to the results obtained in this section, the use of these panels is much more

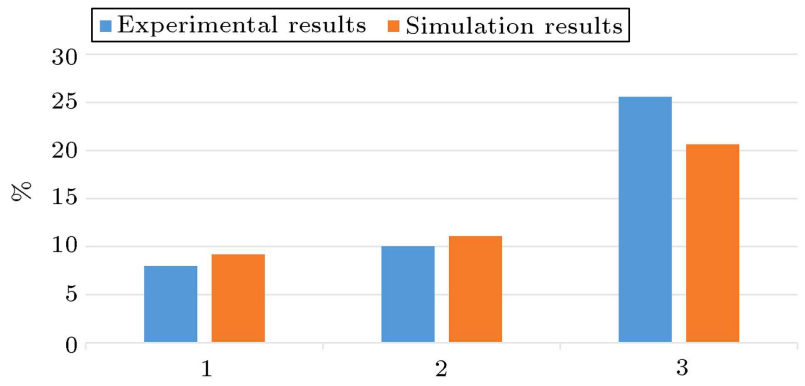

Figure 10. Comparison of experimental and simulation data. efficient in the tracking systems because the temperature has a more negative effect on the tracking systems and the efficiency of the system increases with decreasing temperature. On the other hand, tracking systems generate more heat and photovoltaicthermal panels can generate more thermal energy from these systems. As a result, the use of these panels in tracking systems results in greater electrical and thermal efficiency.

\section{Conclusion}

The effect of such an important parameter as temperature on the fixed and tracking photovoltaic systems may vary. Tracking systems are characterized by higher temperatures because they are directly placed opposite to the sun from the sunrise to sunset. In this paper, an attempt was made to quantitatively calculate this increase in temperature in tracking systems compared to fixed systems. The quantitative calculation is important because it indicates whether the negative impact of temperature on the tracking system is low enough to be ignored, or that this value is significant and cannot be ignored.

The results of the simulation show that in a place like Tehran, Iran where the experiment was carried out, the negative impact of temperature on the tracking system is about $20.65 \%$ higher than the fixed system. This study witnessed $9.2 \%$ and $11.1 \%$ rates of temperature-induced efficiency drop in fixed and tracking systems, respectively. The results of the experiment approximately confirmed these findings. According to the simulation results, the fixed and tracking systems experienced $7.98 \%$ and $10.02 \%$ reductions in temperature-induced efficiency, respectively. According to the obtained numbers, the temperature-induced efficiency drop in the tracking photovoltaic system was $25.55 \%$ higher than that in the fixed photovoltaic system. Observations showed that the largest temperature difference between the systems was at sunrise and sunset when the tracking system was directly facing the sun and the fixed system had the highest angle with sunlight. As it gets closer to noon time, the difference decreased and the temperatures of the two systems became closer together. At noon, the two systems had a nearly identical angle with both of them facing the sun. The difference in power drop due to the temperature above $20 \%$ between fixed and tracking systems indicates that in examining and comparing the types of photovoltaic systems, the vulnerability of the systems to temperature should be examined. This means that although the tracking system is superior to the fixed system with a higher energy production, it is subject to a number of disadvantages. This makes the operating systems more vulnerable to temperature in very hot 
climates. The drop in temperature efficiency is so high that using these systems will no longer be an advantage.

\section{References}

1. Bahrami, M., Gavagsaz-Ghoachani, R., Zandi, M., et al. "Hybrid maximum power point tracking algorithm", Renew. Energy, 130, pp. 982-991 (2019).

2. Akrami, E., Khazaee, I., and Gholami, A. "Comprehensive analysis of a multi-generation energy system by using an energy-exergy methodology for hot water, cooling, power and hydrogen production", Appl. Therm. Eng., 129, pp. 995-1001 (2018).

3. Rouholamini, M. and Mohammadian, M. "Grid-pricedependent energy management of a building supplied by a multisource system integrated with hydrogen", International Journal of Engineering, 29(1), pp. 4048 (2016).

4. Darian, M.M., Ghorreshi, A.M., and Hajatzadeh, M.J. "Evaluation of photovoltaic system performance: A case study in east Azerbaijan, Iran", Iran. J. Energy Environ., 11(1), pp. 75-78 (2020).

5. Zandi, M., Bahrami, M., Eslami, S., et al. "Evaluation and comparison of economic policies to increase distributed generation capacity in the Iranian household consumption sector using photovoltaic systems and RETScreen software", Renew. Energy, 107, pp. 215222 (2017).

6. Kumar, R. and Biswas, A. "Techno-economic optimization of a stand-alone photovoltaic-battery renewable energy system for low load factor situation- a comparison between optimization algorithms", International Journal of Engineering, 30(10), pp. 15551564 (2017).

7. Choudhary, P. and Kumar, R. "Sustainability perspectives- a review for solar photovoltaic trends and growth opportunities", J. Clean. Prod., 227, pp. 589612 (2019).

8. Sahin, A.Z., Ayaz, M., Yilbas, B.S., and Al-shara, A. "Performance enhancement of solar energy systems using nano fluids: An updated review", Renewable Energy, 145, pp. 1126-1148 (2020).

9. Jamila, E. and Abdelmjid, S. "Physical modeling of a hybrid wind turbine-solar panel system using simscape", Int. J. Eng., 27(11), pp. 1767-1776 (2014).

10. Santhakumari, M. and Sagar, N. "A review of the environmental factors degrading the performance of silicon wafer-based photovoltaic modules: Failure detection methods and essential mitigation techniques", Renew. Sustain. Energy Rev., 110, pp. 83-100 (2019).

11. Maftah, A., Maaroufi, M., and Maaroufi, M. "Experimental evaluation of temperature effect of two different PV experimental evaluation of temperature effect of two different PV systems performances under arid climate", Energy Procedia, 157, pp. 701-708 (2019).
12. Salih, S.M., Jabur, Y.K., and Kadhim, L.A. "Analysis of temperature effect on a crystalline silicon photovoltaic module performance", International Journal of Engineering, 29(5), pp. 722-727 (2016).

13. Rad, A.H., Ghadamian, H., Haghgou, H.R., and Sarhaddi, F. "Energy and exergy evaluation of multichannel photovoltaic/thermal hybrid system: Simulation and experiment", International Journal of Engineering, 32(11), pp. 1665-1680 (2019).

14. Aslan Gholamia, A.S. and Alemrajabib, A.A. "Experimental study of self-cleaning property of titanium dioxide and nanospray coatings in solar applications", Sol. Energy, 157, pp. 559-565 (2017).

15. Gholami, A., Khazaee, I., Eslami, S., Zandi, M., and Akrami, E. "Experimental investigation of dust deposition effects on photo-voltaic output performance", Sol. Energy, 159, pp. 346-352 (2018).

16. Subramaniam, K.N.V. and Murugan, E. "Power analysis of non-tracking PV system with low power RTC based sensor independent solar tracking (SIST) PV system", Mater. Today Proc., 5(1), pp. 1076-1081 (2018).

17. Fathabadi, H. "Novel high efficient offline sensorless dual-axis solar tracker for using in photovoltaic systems and solar concentrators", Renew. Energy, 95, pp. 485-494 (2016).

18. Algarín, C.R., Castro, A.O., Naranjo, J.C., Magdalena, U., and Ingeniería, F.D. "Dual-axis solar tracker for using in photovoltaic systems", International Journal of Renewable Energy Research, 7(1), pp. 137-145 (2017).

19. Said, Z. and Mehmood, A. "Standalone photovoltaic system assessment for major cities of United Arab Emirates based on simulated results", J. Clean. Prod., 142, pp. 2722-2729 (2017).

20. Kumar, V. and Kumar, S. "Design and development of dual axis solar panel tracking system for normalized performance enhancement of solar panel", In International Conference on Sustainable Computing in Science, Technology \& Management (SUSCOM-2019), pp. $212-218$ (2019).

21. Afanasyeva, S., Bogdanov, D., Breyer, C., and Shell, R.D. "Relevance of PV with single-axis tracking for energy scenarios German Advisory Council on global change", Sol. Energy, 173, pp. 173-191 (2018).

22. Bahrami, A., Okoye, C.O., and Atikol, U. "Technical and economic assessment of fixed, single and dual2 axis tracking PV panels in low latitude countries", Renew. Energy, 113, pp. 563-579 (2017).

23. Dang, B., Cuong, M., and Ancheta, A.C. "Energy yields of a GPS-based dual-axis solar tracker and a fixed mount PV panel operating in different weather conditions", Journal of Science, Engineering, and Technology, 56, pp. 43-56 (2018).

24. Tseng, K. "Effect of the sun elevation for fixed PV system and single-axis-tracking PV system 1st", 2019 IEEE 6th Int. Conf. Ind. Eng. Appl., pp. 805-809 (2019). 
25. Smirnov, A.A., Vozmilov, A.G., and Romanov, P.A. "Comparison of discrete sun tracking methods for photovoltaic panels", 2019 Int. Conf. Ind. Eng. Appl. Manuf., pp. 1-5 (2019).

26. Eldin, S.A.S., Abd-elhady, M.S., and Kandil, H.A. "Feasibility of solar tracking systems for PV panels in hot and cold regions", Renew. Energy, 85, pp. 228-233 (2016).

27. Simon Heslop, I.M. "Comparative analysis of the variability of fixed and tracking photovoltaic systems Simon", Sol. Energy, 107, pp. 351-364 (2014).

28. Sebastijan Seme, D.K. and Srpčič, G. "Dual-axis photovoltaic tracking system-design and experimental investigation", In Energy, 139, pp. 1267-1274 (2017).

29. Bashar Hammada, A., Al-Sardeahb, A., Al-Abedd, M., Nijmehb, S., and Al-ghandoor, A. "Performance and economic comparison of fixed and tracking photovoltaic systems in Jordan", Renew. Sustain. Energy Rev., 80, pp. 827-839 (2017).

30. "PVSyst - Logiciel Photovoltaïque" (2019). [Online]. Available: www.pvsyst.com.

31. King, D.L., Boyson, W.E., and Kratochvil, J.A., Photovoltaic Array Performance Model (Nov. 2003).

32. Sathe, T.M. and Dhoble, A.S. "A review on recent advancements in photovoltaic thermal techniques", Renew. Sustain. Energy Rev., 76, pp. 645-672 (2017).

33. Sahota, L. and Tiwari, G.N. "Review on series connected photovoltaic thermal (PVT) systems: Analytical and experimental studies", Sol. Energy, 150, pp. 96-127 (2017).

34. Lamnatou, C. and Chemisana, D. "Photovoltaic/ thermal (PVT) systems: A review with emphasis on environmental issues", Renew. Energy, 105, pp. 270287 (2016).
35. Brahim, T. and Jemni, A. "Economical assessment and applications of photovoltaic/thermal hybrid solar technology: A review", Sol. Energy, 153, pp. 540-561 (2017).

36. Aste, N., Del Pero, C., and Leonforte, F. "Water PVT collectors performance comparison", Energy Procedia, 105, pp. 961-966 (2017).

37. "Technical Data Conergy PE 245P-265P" (2019). [Online]. Available at:

https://www.solaris-shop.com/conergy-pe-255p255 w-poly-solar-panel/.

\section{Biographies}

Mahdi Mohammad Mirzaei Darian (1991) is a graduate of Mechanical and Energy Engineering from Shahid Beheshti University. He has studied the blades of gas turbines and applied non-destructive tests to them in the Bachelor's thesis. His field of interest is renewable energy, especially solar energy. He works in the field of installation, maintenance, research and development on photovoltaic systems as well as research on increasing efficiency and manufacturing solar inverters.

Amir Mahdi Ghorreshi (1992) hold a Bachelor's degree in Industrial Engineering from Raja University. His interests lie in renewable energy and energy policy. He works in the field of installation of photovoltaic systems and also studies wind turbines. He is also researching the construction of wind turbines for use in urban space. 